\title{
Transcriptome Profiles and Gene Expression of Min6 Cells Are Altered by Pancreatic Stellate Cells
}

\section{Ratnakar Reddy Bynigeri', Sasikala Mitnala1 ${ }^{*}$, Ravikanth Vishnubhotla', Rupjyoti Talukdar ${ }^{1,2}$, Surya Satyanarayana Singh ${ }^{3}$, Nageshwar Reddy Duvvuru ${ }^{1}$}

\author{
${ }^{1}$ Asian Healthcare Foundation, Hyderabad, India \\ ${ }^{2}$ Asian Institute of Gastroenterology, Hyderabad, India \\ ${ }^{3}$ Osmania University, Hyderabad, India \\ Email: *aigres.mit@gmail.com
}

How to cite this paper: Bynigeri, R.R., Mitnala, S., Vishnubhotla, R., Talukdar, R., Singh, S.S. and Duvvuru, N.R. (2018) Transcriptome Profiles and Gene Expression of Min6 Cells Are Altered by Pancreatic Stellate Cells. Advances in Bioscience and Biotechnology, 9, 273-288.

https://doi.org/10.4236/abb.2018.96018

Received: April 26, 2018

Accepted: June 25, 2018

Published: June 28, 2018

Copyright $\odot 2018$ by authors and Scientific Research Publishing Inc. This work is licensed under the Creative Commons Attribution International License (CC BY 4.0).

http://creativecommons.org/licenses/by/4.0/

(C) (i) Open Access

\begin{abstract}
Aim: To identify the influence of pancreatic stellate cell (PSCs) secretions on gene expression profiles of Min6 cells by whole transcriptome sequencing. Methods: Pancreatic stellate cells (PSCs) were isolated from C57BL6J mice and propagated in vitro to acquire the activated phenotype. Total RNA was isolated from monocultured (MC) and PSC cocultured (CC) Min6 cells to prepare cDNA libraries, which were subjected to whole transcriptome sequencing for identifying differential expression of $\beta$-cell transcription factors $\left(P d x-1, R f_{x} 6\right.$ and NeuroD1) related to insulin gene transcription and GSIS related genes such as Glut2, Gck, Abcc8, Kcnj11 and L-type $\mathrm{Ca}^{2+}$ channels (Cacnb2, Cacna1c). qRT-PCR was used to validate the gene expression. GSIS of Min6 cells was examined by estimating insulin levels in response to high glucose challenge. Results: Transcriptome analysis of discovery set revealed that coculture of Min 6 cells with PSCs caused increased expression of $\beta$-cell specific genes (Ins1, Rfx 6 and NeuroD1) concomitant with decreased expression of $P d x-1, M a f A$ and $N k x 2-2$. Expression of GSIS associated genes (Glut2, Gck, $A b c c 8, K c n j 11$ and $C a c n b 2)$ was decreased in such conditions. Validation by qRT-PCR in Min6 cells cocultured with PSCs revealed increased significant expression of Ins1 (2.1 \pm 0.22 folds; $p \leq 0.001)$, Rfx $6(1.68 \pm 0.23$ folds; $p \leq 0.002)$ and NeuroD1 (0.96 \pm 0.11 folds; $p \leq 0.01)$, accompanied by downregulation of Cacnb2 ( $-0.93 \pm 0.57$ folds; $p \leq 0.05)$. PSC secretions did not restore the GSIS from glucose unresponsive higher passage Min6 cells (MC: $1.33 \pm 0.42$; CC: $1.55 \pm 0.72 \mathrm{pmol} / \mathrm{mg}$ protein; $p=n s$ ) upon high glucose stimulation. However, glucose responsive higher passage Min6 cells cocultured with PSCs presented increased insulin secretion (MC: $7.025 \pm 0.64$; CC:
\end{abstract}


$14.84 \pm 1.01 \mathrm{pmol} / \mathrm{mg}$ protein; $p \leq 0.04)$ concomitant with marginal increase of insulin contents. Conclusion: PSC secretions increase Ins1, RfX 6 and NeuroD1 gene expression, GSIS from glucose responsive Min6 cells, but do not restore the GSIS from glucose unresponsive Min6 cells.

\section{Keywords}

$\beta$-Cells, Gene Expression, Islets, Pancreatic Stellate Cells, Transcriptome

\section{Introduction}

The functioning of pancreatic $\beta$-cells, which perform a pivotal role in maintaining glucose homeostasis, is influenced by various factors including nutritional [1] [2] [3], metabolic [4] [5] and hormonal factors [6] [7] [8], as well as pancreatic inflammatory microenvironment [9] [10] [11] [12]. While islet functions are largely unruffled in healthy individuals, alterations in one or more of these factors cause considerable morbidity experienced in pancreatic disease that may be associated with fibrosis [13] [14] [15], resulting from inflammatory cells and activation of pancreatic stellate cells (PSCs). Elevated levels of pancreatic proinflammatory cytokines such as IL- $1 \beta$, TNF- $\alpha$ and IFN- $\gamma$ encountered in pancreatic fibro-inflammatory disease conditions like chronic pancreatitis (CP) [16], and pancreatic cancer (PC) [17] [18] [19], and emanating from various sources including activated PSCs are known to contribute towards $\beta$-cell damage and impaired insulin secretion. Activated PSCs are also known to secrete IL-6 [20] [21], as well as growth factors such as Activin-A [22], and Hepatocyte Growth Factor (HGF) [23], which are known to promote Glucose Stimulated Insulin Secretion (GSIS) [24]-[29] from $\beta$-cells. In addition, the accumulation of PSCs in peri-islet regions and PSC infiltration [14] [15] [30] [31] into the islets of patients with $\mathrm{CP}$ and PC also suggest a probable role for PSCs in influencing $\beta$-cell function associated with pancreatic disease.

Recent studies with rodents involving coculture of activated PSCs with islets and with $\beta$ cell lines indicated variable influence of PSCs on insulin secretory response of $\beta$-cells. Rat insulinoma cell lines (RINm-5F, INS-1) showed decreased insulin secretion [14] [32] when cocultured with PSCs or incubated with PSC conditioned medium. In yet another study, increased insulin secretory response associated with a decrease in total insulin content was reported when mouse islets were cocultured with PSCs [33]. Availability of adequate information regarding gene expression in $\beta$-cells in response to the presence of PSCs in coculture conditions, would resolve these observations and comprehensively elucidate the influence of PSCs on $\beta$-cell functions. In view of these considerations, the present study involving indirect coculture of Min6 cells with activated PSCs was aimed to 1) study the transcriptome profile alterations and the accompanying 2) expression of $\beta$-cell specific transcription factors and GSIS related genes in Min6 cells. 


\section{Materials and Methods}

\subsection{Chemical}

All the chemicals used in the experiments are obtained from Sigma unless otherwise mentioned.

\subsection{Cells and Culture Conditions}

\section{Mouse insulinoma cells}

Min6 cells were obtained from National Centre for Cell Sciences, Pune, India as well as from AddexBio, San Diego, USA. Min6 cells were routinely cultured in DMEM containing $25 \mathrm{mM}$ glucose supplemented with 15\% FBS in T25 flasks and maintained in a humidified chamber with $5 \% \mathrm{CO}_{2}$ at $37^{\circ} \mathrm{C}$. Where required, Min6 cells at lower passage (P11) were cultured to higher passages (P53-64) under the above conditions.

\section{Isolation and activation of pancreatic stellate cells}

Male C57BL6J mice (approximately three months old) were purchased from National Centre for Laboratory Animal Sciences, Hyderabad and were used to isolate the quiescent stellate cells from mouse pancreas as per the method described earlier [34], with minor modifications. Briefly, surgically resected mouse pancreatic tissue was inflated by injecting Hank's balanced salt solution (HBSS) containing Collagenase P (Roche, Germany), Protease type IV and DNase I (Roche, Germany). The distended tissue was incubated in a shaking water bath at $37^{\circ} \mathrm{C}$ for $5-7$ minutes. Finely minced tissue was further incubated at $37^{\circ} \mathrm{C}$ for 5 minutes in a shaking water bath. The digested tissue was then centrifuged and pelleted at $450 \times \mathrm{g}$ for 10 minutes. The resultant supernatant was discarded and the pellet was resuspended in HBSS containing 0.3\% BSA and centrifuged. The obtained pellet was resuspended in $10 \mathrm{~mL}$ of $0.3 \%$ BSA containing HBSS and 8 $\mathrm{mL}$ of Nycodenz ${ }^{\circ}$ (Axis Shield, Norway) gradient solution. The cell suspension was carefully layered under HBSS buffer containing $0.3 \%$ BSA and centrifuged at $1400 \times \mathrm{g}$ for 20 minutes at $4^{\circ} \mathrm{C}$. The fuzzy band formed at the interphase was collected and centrifuged at $450 \times \mathrm{g}$ for 10 minutes. The obtained pellet with primary cells was suspended in IMDM (Himedia, India) containing 20\% FBS (Himedia, India) along with $1 \%$ penicillin and streptomycin (Himedia, India). The quiescent phenotype of isolated PSCs was ascertained by appearance of lipid droplets within $6-8$ hours. These primary cells are subsequently passaged to obtain the activated phenotype of PSCs under in vitro conditions. All the indirect coculture experiments are conducted using activated PSCs of passage 3.

\subsection{Indirect Coculture of PSCs with Min6 Cells}

Min6 cells were subjected to indirect coculture with activated PSCs using transwell inserts with polycarbonate membrane (Himedia, India) having a pore size of $0.4 \mu \mathrm{m}$ as per the method described earlier [14] [35]. PSCs $\left(25 \times 10^{3}\right.$ cells $)$ suspended in complete IMDM were seeded on a transwell insert followed by seeding of Min6 cells $\left(0.25 \times 10^{6}\right.$ cells $)$ suspended in complete DMEM into the 
culture well plate. After separate incubation of cells for 24 - 36 hours, the spent media were replaced with fresh media and culture inserts with PSCs were placed in culture wells containing Min6 cells. Incubation was continued for the next 72 hours followed by harvesting Min6 cells for further studies involving RNA isolation, transcriptome profiling and qRT-PCR validation of the target gene expression as well as GSIS assays.

\subsection{Whole Transcriptome Sequencing}

Total RNA was isolated from Min6 cells employing RNeasy kit (Qiagen, Germany) as per the manufacturer's protocol. Quantity and quality of the isolated RNA was assessed using Bioanalyzer 2100 (Agilent, Germany) and samples which showed RNA integrity number $>8$ were used in this study. Whole transcriptome sequencing was performed on monocultured and PSC cocultured Min6 cells samples employing Ion Total RNA-Seq kit V2, including Ion RNA-Seq Core kit v2, Ion RNA-Seq Primer Set (Life technologies, USA). Briefly, $5 \mu \mathrm{g}$ of total RNA was purified using RiboMinus ${ }^{\text {Tx }}$ Eukaryote System v2 Kit to obtain rRNA-depleted total RNA. RNA thus obtained was fragmented using RNase III for 10 minutes and purified using magnetic beads. Purified RNA was quantitated on Agilent Bioanalyzer using RNA 6000 Pico Kit which yielded fragments in the range of $100-200$ nucleotides. Whole transcriptome libraries were constructed by hybridizing and ligating the RNA and subjected to reverse transcription. The obtained cDNA was purified and amplified by polymerase chain reaction. The yield and size distribution of the amplified cDNA was assessed; barcoded pooled transcriptome libraries were sequenced on Proton Semiconductor Sequencer (Ion torrent, Life Technologies, USA). Whole transcriptome sequencing was performed using a single set of total RNA samples isolated from monocultured and PSC cocultured Min6 cells. Sequencing reads were assessed for quality and single-end mRNA reads were mapped onto Mouse genome $(\mathrm{mm} 10)$ and analyzed using Partek Genomics Suite v6.6. BAM files were imported into the software; samples were assigned the respective attributes using categorical (Coculture Vs Monoculture) variables.

\subsection{Gene Expression Studies}

\section{Validation of target gene expression by $q R T-P C R$}

Total RNA was isolated from both monocultured and PSC cocultured Min6 cells using TRIzol $^{\circledR}$ reagent (Ambion ${ }^{\oplus}$, Life Technologies, USA) as per the manufacturer's protocol. $1 \mu \mathrm{g}$ of total RNA was used to synthesize the cDNA reaction using Superscript IV First-Strand Synthesis System (Invitrogen, Lithuania) in a total volume of $20 \mu \mathrm{L}$ reaction setup. The prepared cDNA was used to validate the differential expression of $\beta$-cell specific and GSIS related genes that were identified in the discovery study, using the Power Sybr ${ }^{\bullet}$ green PCR Master Mix (Applied Biosystems, United Kingdom) on Step One ${ }^{\otimes}$ Real Time PCR System (Applied Biosystems, Singapore). Forward and reverse primer sequences for the target genes used in this study are listed in Table 1. Relative target gene 
Table 1. Primer sequences used in qRT-PCR study.

\begin{tabular}{|c|c|c|c|}
\hline Gene & Transcript ID & Forward and Reverse Primer Sequences & Amplicon Size (bp) \\
\hline \multirow[t]{2}{*}{ Ins1 } & NM_008386 & 5-GCCCTTAGTGACCAGCTATAATC-3 & 154 \\
\hline & & 5-GGACCACAAAGATGCTGTTTG-3 & \\
\hline \multirow[t]{2}{*}{$P d x-1$} & NM_008814 & 5-GAAATCCACCAAAGCTCACG-3 & 190 \\
\hline & & 5-CAAGTTCAACATCACTGCCAG-3 & \\
\hline \multirow[t]{2}{*}{$R f x 6$} & NM_001159389 & 5-CGGTGCATTCTTTATGCTCA-3 & 219 \\
\hline & & 5-TGTCAAGCCCTTTCCAGAAT-3 & \\
\hline \multirow[t]{2}{*}{ MafA } & NM_194350 & 5-GAGGTCATCCGACTGAAACAG-3 & 203 \\
\hline & & 5-GCCAACTTCTCGTATTTCTCCT-3 & \\
\hline \multirow[t]{2}{*}{ NeuroD1 } & NM_010894 & 5-CCAGGGTTATGAGATCGTCAC-3 & 171 \\
\hline & & 5-TTCTTGTCTGCCTCGTGTTC-5 & \\
\hline \multirow[t]{2}{*}{$N k \times 2-2$} & NM_001077632 & 5-TTCCATAACCATCGCTACAAG-3 & 236 \\
\hline & & 5-TTGGCATTGTGGTCCTACTG-3 & \\
\hline \multirow[t]{2}{*}{ Glut2 } & NM_031197 & 5-CTTGGCTTTCACTGTCTTCAC-3 & 220 \\
\hline & & 5-GTGAGCAGATCCTTCAGTCTC-3 & \\
\hline \multirow[t]{2}{*}{ Gck } & NM_010292 & 5-GGATGACAGAGCCAGGATG -3 & 219 \\
\hline & & 5-TGGGCAACATCTTTACACTGG -3 & \\
\hline \multirow[t]{2}{*}{$A b c c 8$} & NM_011510.3 & 5-TGCTCTTTGTCCTGGTGTG-3 & 140 \\
\hline & & 5-GTCCAGTAGATAAGCAGAGCG-3 & \\
\hline \multirow[t]{2}{*}{ Kcnj11 } & NM_001204411 & 5-GAGGACGGGCTCACAGAC-3 & 155 \\
\hline & & 5-CACCAGACCATGGCAAAG-3 & \\
\hline \multirow[t]{2}{*}{ Cacnb2 } & NM_023116 & 5-CAGCCTTGGAGTCGACTTTTT -3 & 205 \\
\hline & & 5-СТАTTTTTCCTCCTGGCTCCTT -3 & \\
\hline \multirow[t]{2}{*}{ Cacnalc } & NM_001256001 & 5-TTCTTCCTCTTTGTGGCTTCT-3 & 233 \\
\hline & & 5-CAGCTGCATTGGCATTCAT-3 & \\
\hline \multirow[t]{2}{*}{ Mtpn } & NM_008098 & AAAACGGAGACTTGGATGAGG & 247 \\
\hline & & TCAGCACCCTTTGACAGAAG & \\
\hline \multirow[t]{2}{*}{$\beta$-Actin } & NM_007393 & 5-CATCCGTAAAGACCTCTATGCC-3 & 231 \\
\hline & & 5-GACTCATCGTACTCCTGCTTG-3 & \\
\hline
\end{tabular}

expression was normalized to the expression levels of $\beta$-actin. The fold difference between the monoculture and coculture samples was calculated by using Pfaffl's $2^{-\Delta \Delta C t}$ method and the obtained values were $\log 2$ transformed.

\subsection{Glucose Stimulated Insulin Secretion}

Glucose Stimulated Insulin Secretion (GSIS) from Min6 cells was examined as per the method described earlier [24]. Min6 cells were incubated in Krebs-Ringer bicarbonate with Hepes $(\mathrm{KRBH})$ buffer containing $(\mathrm{mmol} / \mathrm{L})$ : $\mathrm{NaCl}, 120 ; \mathrm{KCl}, 5 ; \mathrm{CaCl}_{2}, 2.56 ; \mathrm{MgCl}_{2}, 1.1 ; \mathrm{NaHCO}_{3}, 25 ;$ Hepes (Himedia), 10; along with $0.2 \%$ Bovine Serum Albumin, $\mathrm{pH}$ 7.4. After incubation at $37^{\circ} \mathrm{C}$ for 72 
hours, the cells were washed twice in KRBH buffer and pre-incubated in KRBH containing $2.5 \mathrm{mM}$ glucose for 30 minutes. The cells were incubated for one hour in presence of $2.5 \mathrm{mM}$ (basal) glucose, followed by stimulation with $25 \mathrm{mM}$ (high) glucose, for another hour. The cell supernatants collected after basal and high glucose stimulation were stored at $-20^{\circ} \mathrm{C}$ until further use.

\subsection{Measurement of Insulin Contents in Min6 Cells}

Min6 cells were lysed in Radio Immuno Precipitation Assay (RIPA) buffer (Cell Signaling Technologies, USA) and incubated on ice for 5 minutes. The cell lysates were then briefly sonicated and centrifuged at $14,000 \times \mathrm{g}$ for 10 minutes at $4^{\circ} \mathrm{C}$. The concentration of the total protein in these samples was measured using Bradford's method. The supernatants were collected and stored at $-20^{\circ} \mathrm{C}$ until further use to measure the total insulin content. Insulin was estimated using mouse insulin ELISA (Mercodia, Sweden) kit and OD was recorded at $450 \mathrm{~nm}$ on a microplate reader (BioRad Model 680, Japan). Insulin contents were normalized to total protein and expressed in terms of pmoles of insulin per mg protein.

\subsection{Statistical Analysis}

Probability $(p)$ values between the MC and CC groups were calculated using Student's $t$-test using Microsoft Excel program. Data are represented as mean + /- SEM. $p \leq 0.05$ is considered to be statistically significant.

\section{Results}

\subsection{Whole Transcriptome Analysis Identifies Differentially Expressed Genes in Higher Passage Min6 Cells Cocultured with PSCs}

The discovery set of cDNA libraries, with an average size of 248 and $269 \mathrm{bp}$ length respectively, were prepared from Min6 cells cultured in presence or in absence of PSCs and subjected to whole transcriptome sequencing. These cDNA libraries generated $\approx 67$ million reads with a mean length of $107 \mathrm{bp}$ and $54 \%$ usable reads for MC higher passage Min6 cells and $\approx 58$ million reads with 92 bp as mean length and $46 \%$ usable reads for CC samples. The usable reads obtained from the whole transcriptome sequencing were aligned separately on to the mouse mm10 reference genome, which identified 29610 transcripts during the analysis. Expression levels of the transcripts were normalized as reads per kilobase per million mapped reads (RPKM) to identify the differentially expressed genes. Of all the genes subjected to transcriptome analysis in the discovery set, important changes could be noted with regard to increased expression of $\beta$-cell specific genes such Ins1 (1.68 folds), Rfx 6 (2.33 folds) and NeuroD1 (1.31 folds) accompanied with decreased expression of $P d x 1$ ( -1.92 folds), MafA $(-2.32$ folds), Nkx2-2 (-1.46 folds) and GSIS associated genes such as Glut2 $(-3.28$ folds), Gck (-1.10), Abcc8 (-1.61 folds), Kcnj11 (-2.36 folds), Cacnb2 (-2.97 folds) and Cacnalc ( -1.30 folds). These results are depicted in Table 2 with their respective reads and RPKM values. 
Table 2. List of differentially expressed $\beta$-cell specific and GSIS related genes in PSC cocultured higher passage Min6 cells identified in whole transcriptome analysis from the discovery set. Reads, Reads Per Kilobase Million (RPKM) values and the respective fold changes for the mentioned genes were obtained after analysis of the data using Partek Genomics Suite v6.6.

\begin{tabular}{|c|c|c|c|c|c|c|}
\hline Transcript ID & Gene & Reads (MC) & Reads (CC) & $\begin{array}{c}\text { RPKM } \\
(\mathrm{MC})\end{array}$ & RPKM (CC) & $\begin{array}{l}\text { Fold Change } \\
\text { (in CC) }\end{array}$ \\
\hline NM_008386 & Ins1 & 215373 & 361863 & 5659.18 & 11267.6 & 1.68017 \\
\hline NM_001185083 & Ins2 & 3793.6 & 5540.4 & 126.461 & 218.863 & 1.46046 \\
\hline NM_001185084 & Ins2 & 91252 & 36758.9 & 2447.11 & 1168.15 & -2.48245 \\
\hline NM_008387 & Ins2 & 42757.4 & 42740.5 & 1389.78 & 1646.26 & -1.0004 \\
\hline NM_008814 & $P d x 1$ & 16627 & 8647 & 201.983 & 124.478 & -1.92286 \\
\hline NM_001159389 & $R f_{x} 6$ & 272 & 633.999 & 1.23012 & 3.39777 & 2.33088 \\
\hline NM_177306 & $R f_{x} 6$ & 0.000466417 & 0.00266188 & $2.36 \mathrm{E}-06$ & $1.60 \mathrm{E}-05$ & 5.70708 \\
\hline NM_194350 & MafA & 9398 & 4038 & 136.048 & 69.2703 & -2.32739 \\
\hline NM_010894 & NeuroD1 & 3514 & 4638 & 22.0285 & 34.4539 & 1.31986 \\
\hline NM_001077632 & $N k \times 2-2$ & 336.332 & 166.843 & 3.88355 & 2.28293 & -2.01587 \\
\hline NM_010919 & $N k \times 2-2$ & 1095.67 & 747.992 & 8.36017 & 6.76331 & -1.46481 \\
\hline NM_144955 & Nkx6-1 & 3717 & 1550 & 32.3748 & 15.9982 & -2.39806 \\
\hline NM_001159925 & Pax4 & 0 & 2.96899 & 0 & 0.0417347 & NC \\
\hline NM_001159926 & $\operatorname{Pax} 4$ & 0 & 3.31972 & 0 & 0.0467713 & $\mathrm{NC}$ \\
\hline NM_011038 & $\mathrm{Pax} 4$ & 0 & 0.711296 & 0 & 0.00971125 & NC \\
\hline NM_001244198 & Pax6 & 302.777 & 224.771 & 1.29655 & 1.1406 & -1.34705 \\
\hline NM_001244201 & Pax6 & 510.772 & 367.411 & 2.21269 & 1.88612 & -1.39019 \\
\hline NM_001244200 & Pax6 & 1512.37 & 787.479 & 6.34593 & 3.91562 & -1.92052 \\
\hline NM_001310144 & Pax6 & 2529.64 & 1276.08 & 10.7354 & 6.41744 & -1.98236 \\
\hline NM_001244202 & Pax6 & 320.591 & 256.054 & 1.20341 & 1.13899 & -1.25204 \\
\hline NM_013627 & Pax6 & 203.656 & 167.305 & 0.756839 & 0.736784 & -1.21727 \\
\hline NM_001310145 & Pax6 & 40.8918 & 18.1927 & 0.181263 & 0.0955644 & -2.2477 \\
\hline NM_001310146 & Pax6 & 70.2081 & 30.1526 & 0.314966 & 0.160297 & -2.32842 \\
\hline NM_031197 & $\begin{array}{l}\text { Slc2a2 } \\
\text { (Glut2) }\end{array}$ & 82 & 25 & 0.498838 & 0.180223 & -3.28 \\
\hline NM_001287386 & Gck & 2.07337 & 0.300956 & 0.0136717 & 0.00235167 & -6.88927 \\
\hline NM_010292 & Gck & 614.928 & 556.699 & 3.52548 & 3.78216 & -1.1046 \\
\hline NM_011510 & $A b c c 8$ & 20209 & 12511 & 63.8033 & 46.8075 & -1.6153 \\
\hline NM_001204411 & Kcnj11 & 295.043 & 330.939 & 1.72958 & 2.29895 & 1.12166 \\
\hline NM_010602 & Kcnj11 & 7004.72 & 2959.99 & 35.157 & 17.605 & -2.36647 \\
\hline NM_001252533 & Cacnb2 & 33.2901 & 11.1948 & 0.136463 & 0.0543803 & -2.9737 \\
\hline NM_001309519 & Cacnb2 & 12.8203 & 0.358676 & 0.0515395 & 0.00170871 & -35.7434 \\
\hline NM_023116 & Cacnb2 & 962.894 & 512.447 & 3.81602 & 2.40661 & -1.87901 \\
\hline NM_001159533 & Cacnalc & 478.524 & 389.614 & 0.550427 & 0.531074 & -1.2282 \\
\hline NM_001159534 & Cacnalc & 564.212 & 431.145 & 0.64899 & 0.587685 & -1.30864 \\
\hline NM_001159535 & Cacnalc & 450.751 & 375.024 & 0.51871 & 0.511413 & -1.20192 \\
\hline
\end{tabular}




\begin{tabular}{lllcccc} 
Continued & & & & & \\
\hline NM_001255997 & Cacnalc & 33.1207 & 19.3569 & 0.0388171 & 0.0268834 & -1.71106 \\
NM_001255998 & Cacnalc & 26.2488 & 18.2617 & 0.0305914 & 0.0252205 & -1.43737 \\
NM_001255999 & Cacnalc & 27.7333 & 17.35 & 0.0325031 & 0.0240962 & -1.59846 \\
NM_001256000 & Cacnalc & 498.247 & 599.278 & 0.571348 & 0.814346 & 1.20277 \\
NM_001256001 Cacnalc & 907.42 & 1101.3 & 1.03987 & 1.49554 & 1.21366 \\
NM_001256002 & Cacnalc & 381.026 & 383.143 & 0.430394 & 0.512859 & 1.00556 \\
NM_001290335 Cacnalc & 26.1866 & 16.2691 & 0.0323491 & 0.0238161 & -1.60959 \\
NM_009781 & Cacnalc & 27.5241 & 17.269 & 0.032258 & 0.0239837 & -1.59384 \\
NM_001083616 Cacnald & 360.529 & 251.773 & 0.622008 & 0.514742 & -1.43196 \\
NM_001302637 & Cacnald & 249.841 & 186.019 & 0.426104 & 0.375953 & -1.34309 \\
NM_028981 & Cacnald & 90.4243 & 111.495 & 0.162721 & 0.237761 & 1.23302 \\
NM_001081023 & Cacna1s & 1.1352 & 1.892 & 0.00283924 & 0.00560758 & 1.66667 \\
NM_014193 & Cacna1s & 1.8648 & 3.108 & 0.00471152 & 0.0093054 & 1.66667 \\
\hline
\end{tabular}

\section{2. qRT-PCR Validation Identifies Increased Expression of Ins1, Rfx-6 and NeuroD1 Genes in PSC Cocultured Higher Passage Min6 Cells}

Changes in the expression levels of $\beta$-cell related genes observed in the discovery set were validated by qRT-PCR. In comparison to Min6 cells cultured in absence of PSCs, those cultured in presence of PSCs revealed increased expression levels of Ins1 (2.1 \pm 0.22 folds; $p \leq 0.001), R f_{x} 6(1.68 \pm 0.23$ folds; $p \leq 0.002)$ and NeuroD1 ( $0.96 \pm 0.11$ folds; $p \leq 0.01$ ), concomitant with decreased expression of MafA $(-0.82 \pm 0.29$ folds; $p \leq 0.05)$ and $N k x 2-2(-0.43 \pm 0.44$ folds; $p \leq 0.39)$ genes, without significant change in $P d x-1$ expression ( $0.4 \pm 0.57$ folds; $p \leq 0.57)$ (Figure 1(a)).

\subsection{PSCs Do Not Alter the Expression of GSIS Related Genes in Higher Passage Min6 Cells}

As in case of $\beta$-cell related genes, changes in the expression levels of GSIS associated genes are also validated by qRT-PCR. Although the expression levels of Glut2 ( $-1.12 \pm 0.76$ folds; $p \leq 0.76)$, potassium channel subunit $A b c c 8(-0.61 \pm$ 0.38 folds; $p \leq 0.18)$ and L-type calcium channel subunit Cacnb2 $(-0.93 \pm 0.57$ folds; $p \leq 0.05$ ) were decreased as in the discovery set, results of the validation revealed no statistically significant change in the expression levels between mono and PSC cocultured Min6 cells. Although not significant, marginal increase in the expression of $G c k(0.63 \pm 0.81$ folds; $p \leq 0.48)$ and potassium channel subunit Kcnj11 ( $0.53 \pm 0.57$ folds; $p \leq 0.40)$ were noticed in PSC cocultured Min6 cells compared to monocultured Min6 cells. The L-type calcium channel, Cacnalc $(0.60 \pm 0.38$ folds; $p \leq 0.38)$ also did not show any significant increase in its expression (Figure 1(b)), which was noticed to be upregulated by 1.2-fold in the discovery study. 


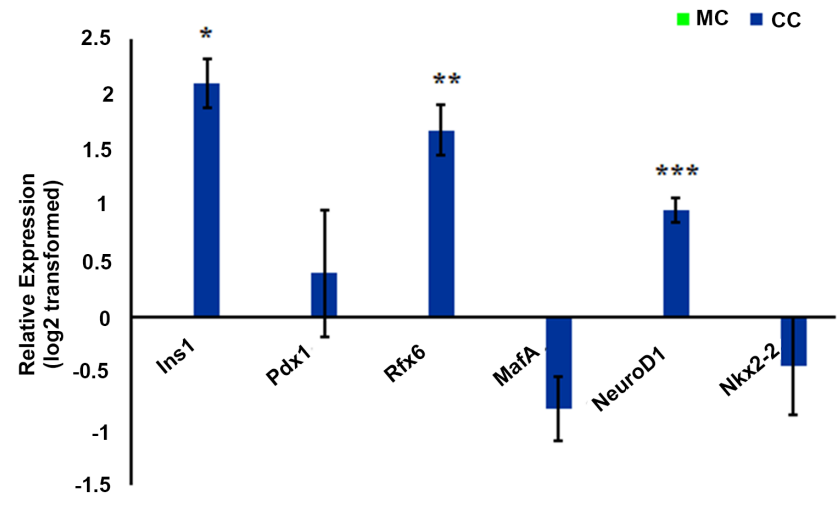

(a)

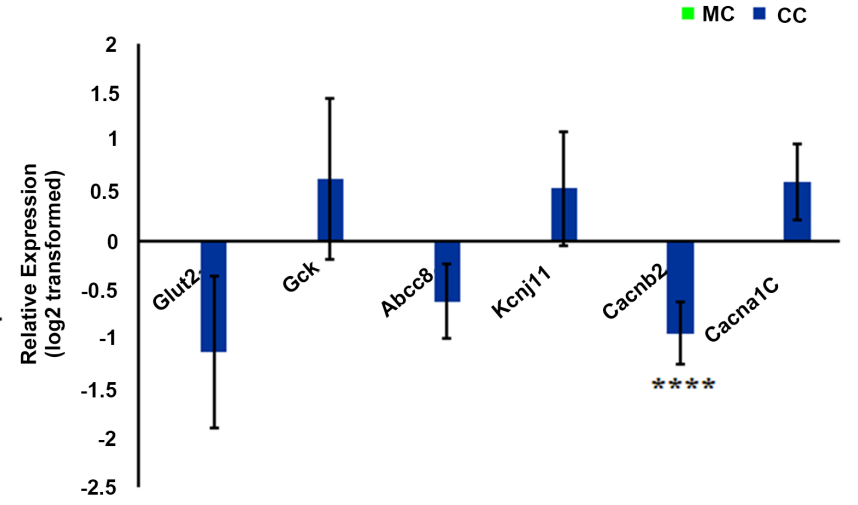

(b)

Figure 1. Relative expression of $\beta$-cell specific and GSIS related genes in PSC cocultured higher passage Min6 cells: (a) PSC cocultured Min6 cells showing a significant increase in the expression levels of Ins1, Rfx 6 and NeuroD1, while Pdx $1, M a f A$ and Nkx2-2 expression levels were seen unaltered; (b) GSIS associated genes such as Glut2, Gck, Abcc8, Kcnj11 and Cacnalc showing no significant change in their expression levels while Cacnb2, showed significant downregulation in PSC cocultured Min6 cells (n $=5$ ). $\beta$-actin was used as an endogenous control to normalize the gene expression levels. Fold changes were calculated using $2^{-\Delta \Delta \mathrm{Ct}}$ method and values were log transformed. Each target gene studied was analysed in duplicates. Data are represented as mean \pm SEM. ${ }^{\star} p \leq 0.001,{ }^{* *} p \leq 0.002,{ }^{* *} p \leq 0.01,{ }^{* * *} p \leq 0.05$. MC $=$ Monoculture, CC $=$ Coculture.

\subsection{PSC Secretions Do Not Restore GSIS from Higher Passage Glucose Unresponsive Min6 Cells}

GSIS response of Min6 cells at high passage (P53-64) was examined when they were cultured in presence or in absence of PSC secretions and the obtained results are depicted in Figure 2(a). It was noted that the high passage Min6 cells used in this study are unresponsive to high $(25 \mathrm{mM})$ glucose stimulation and coculturing such cells with of PSC (MC: $1.33 \pm 0.42$; CC: $1.55 \pm 0.72 \mathrm{pmol} / \mathrm{mg}$ protein; $p=n s$ ) did not reveal any statistically significant changes (Figure 2(a)). However, repeated subculturing of Min6 cells from passage 11 to passage 53-64 resulted in enhanced glucose responsiveness (MC: $7.025 \pm 0.64$; CC: $14.84 \pm 1.01$ $\mathrm{pmol} / \mathrm{mg}$ protein; $p \leq 0.04$ ) of Min6 cells when cocultured with PSCs compared to monocultured Min6 cells (Figure 3(a)), suggesting that the influence of PSC secretions is dependent on the ability of Min6 cells to respond to high glucose stimulation. As shown in Figure 2(b), the total insulin contents of glucose unresponsive higher passage Min6 cells were found to be $251.31 \pm 53.95$ and 296.37 $\pm 56.75 \mathrm{pmol} / \mathrm{mg}$ protein $(p \leq 0.59)$, whereas the glucose responsive higher passage Min6 cells showed $4871.94 \pm 1271.23$ and $6454.03 \pm 474.21 \mathrm{pmol} / \mathrm{mg}$ protein $(p \leq 0.51)$ (Figure $3(\mathrm{~b}))$ in respective monocultured and PSC cocultured Min6 cells.

\subsection{Increased Expression of Ins1, Rfx 6 and NeuroD1 in PSC Cocultured Glucose Responsive Higher Passage Min6 Cells}

Similar to glucose unresponsive higher passage Min6 cells, we found a significant upregulation of Ins1 (0.82 \pm 0.07 folds; $p \leq 0.008), R f_{x} 6$ ( $0.95 \pm 0.18$ folds; $p$ $\leq 0.04)$ and NeuroD1 $(0.93 \pm 0.14$ folds; $p \leq 0.03)$, with a concomitant but not significant decrease in the expression of $P d x-1(-0.28 \pm 0.54$ folds; $p \leq 0.65)$, 


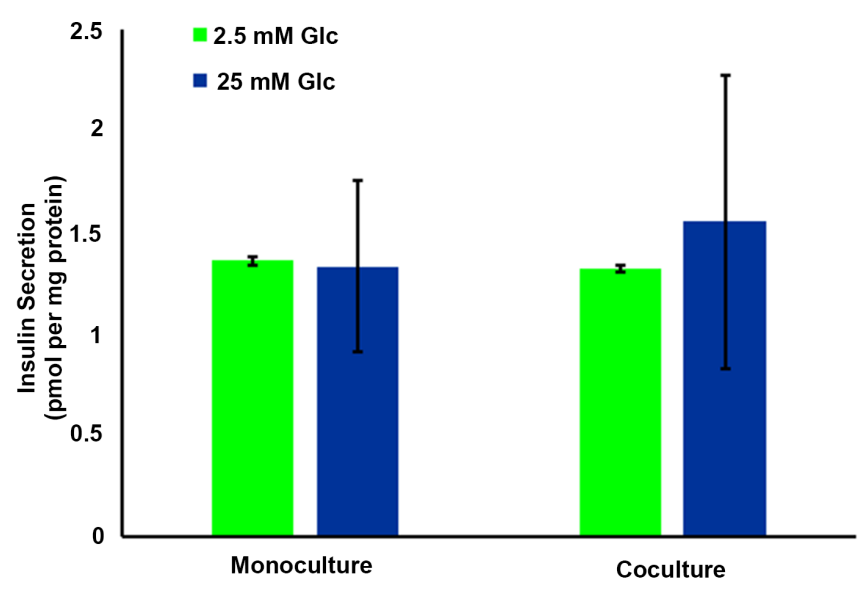

(a)

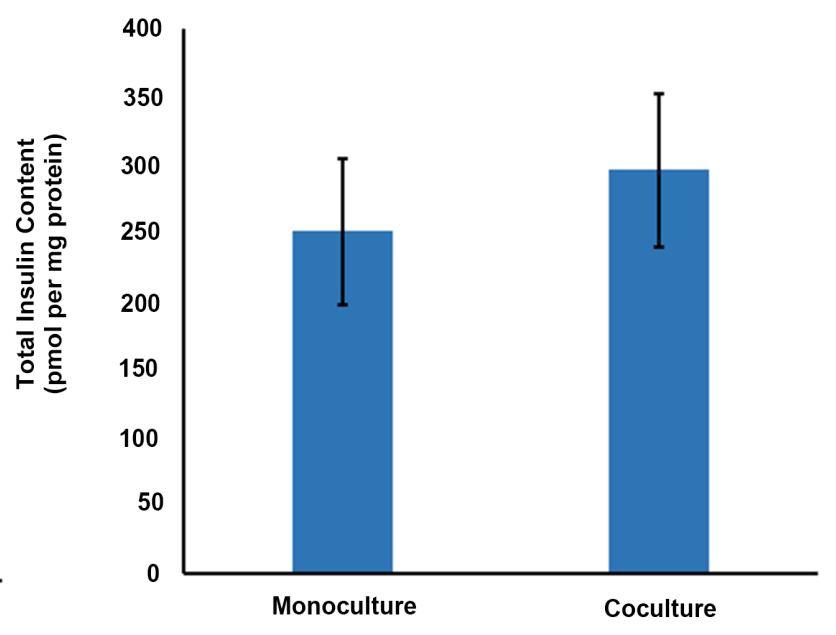

(b)

Figure 2. Impaired GSIS response from higher passage Min6 cells: (a) Mono and PSC cocultured Min6 cells showing no significant change in the amount of insulin secreted when subjected to high $(25 \mathrm{mM})$ glucose stimulation $(\mathrm{n}=4)$, compared to basal $(2.5$ $\mathrm{mM}$ ) glucose, suggesting the impaired glucose sensing ability of these higher passage Min6 cells; (b) PSC cocultured Min6 cells showing a marginal but not significant increase in the total insulin contents compared to monocultured Min6 cells ( $\mathrm{n}=3$ ). Insulin secretion and insulin content was normalized to protein levels. Each sample was quantitated in duplicates and data are represented as mean \pm SEM. $p=$ ns. GSIS $=$ Glucose Stimulated Insulin Secretion. Glc $=$ Glucose.

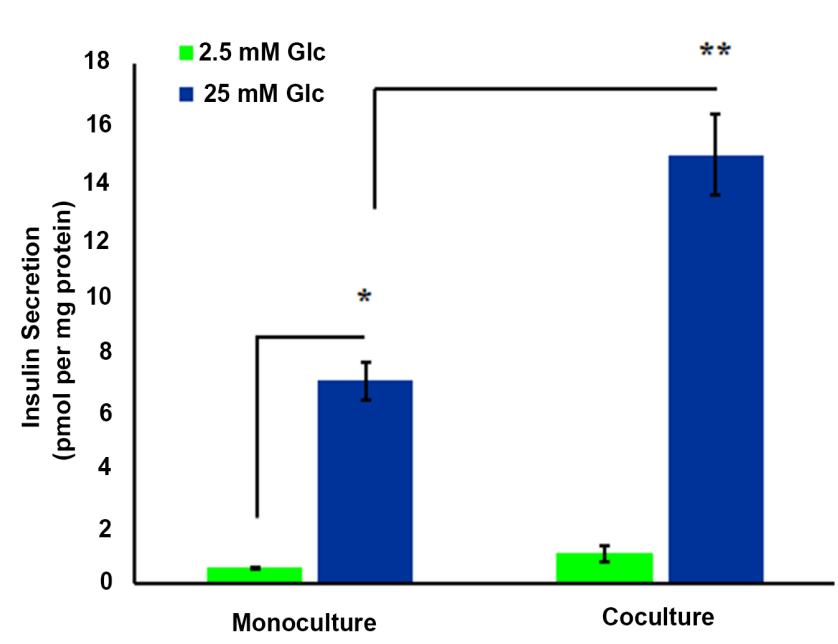

(a)

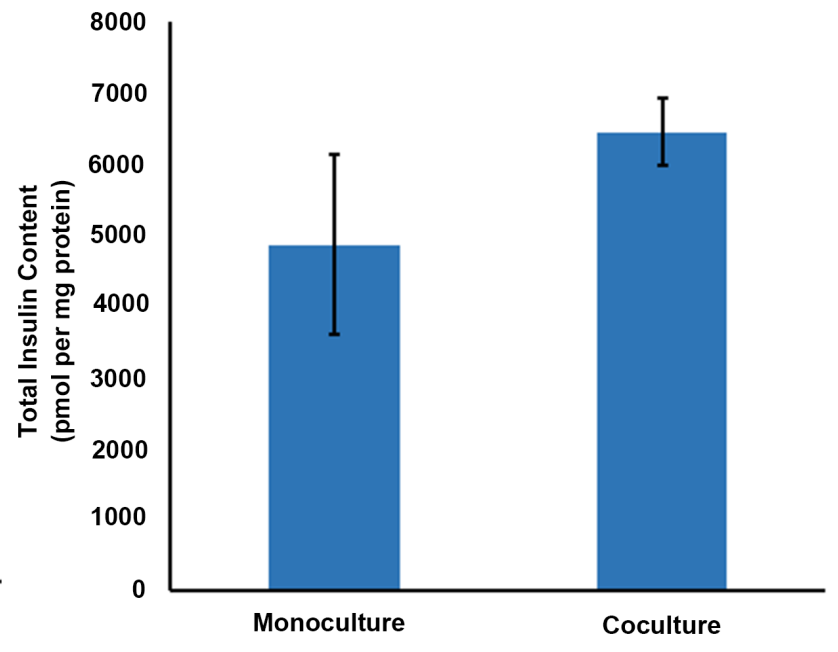

(b)

Figure 3. Pancreatic stellate cells potentiate the insulin secretion from glucose responsive higher passage Min6 cells: (a) Glucose responsive higher passage Min6 cells showing augmented insulin secretion from PSC cocultured Min6 cells compared to Min6 cells in monocultures in response to high $(25 \mathrm{mM})$ glucose stimulation $(\mathrm{n}=4)$; (b) PSC cocultured Min6 cells showing mild but not significant increase in total insulin content levels similar to PSC cocultured glucose unresponsive higher passage Min6 cells compared to monocultured Min6 cells $(\mathrm{n}=4, p=\mathrm{ns})$. Insulin secretion and total insulin content levels were normalized to total protein. Each sample was analysed in duplicates and data are presented as mean \pm SEM. ${ }^{\star} p \leq 0.02$ Vs basal glucose stimulation in monocultured Min6 cells, ${ }^{* *} p \leq 0.04$ Vs monocultured Min6 cells stimulated with high (25 mM) glucose.

MafA $(1.15 \pm 0.65$ folds; $p \leq 0.22)$ and $N k \times 2-2(-1.5 \pm 0.71$ folds; $p \leq 0.61)$ in glucose responsive higher passage Min6 cells. Unlike PSC cocultured glucose unresponsive higher passage Min6 cells, Cacnb2 (1.84 \pm 0.38 folds; $p \leq 0.05)$ along with Cacnalc (1.75 \pm 0.123 folds; $p \leq 0.005)$ showed increased gene ex- 
pression in glucose responsive higher passage Min6 cells. Glut2 $(0.72 \pm 0.22$ folds; $p \leq 0.08), G c k(1.42 \pm 0.56$ folds; $p \leq 0.12), A B C C 8(0.93 \pm 1.0$ folds; $p \leq$ $0.45)$ were upregulated, while $K c n j 11$ ( $-1.15 \pm 2.33$ folds; $p \leq 0.67)$ expression was found to be decreased with no statistical significance (Figure 4(a) \& Figure 4(b)).

\section{Discussion}

The present communication describes results obtained upon culturing Min6 cells exposed to secretions of pancreatic stellate cells. Although PSC infiltration into the islets was demonstrated earlier in pancreatic disease including chronic pancreatitis and pancreatic cancer as well as in diabetic rodent models [14] [15] [30] [31], their influence on $\beta$-cell function is not well understood. Hence the aim of the present study was to identify the influence of activated PSC secretions on global gene expression profile and study the insulin secretory responses in Min6 cells under in vitro conditions. The transwell inserts used in the present communication were advantageous since they permit interactions between secretions of PSCs kept in the upper chamber with Min6 cells present in the lower chamber. Data obtained using such an experimental setup indicated that PSC secretions do influence gene expression and functional ability of Min6 cells to secrete insulin in response to high glucose challenge.

Genes related to synthesis and secretion of insulin were differentially expressed in response to PSC secretions in the discovery study. While expression levels of Ins1, Rfx 6 and NeuroD1 were increased, those of MafA and Nkx2-2

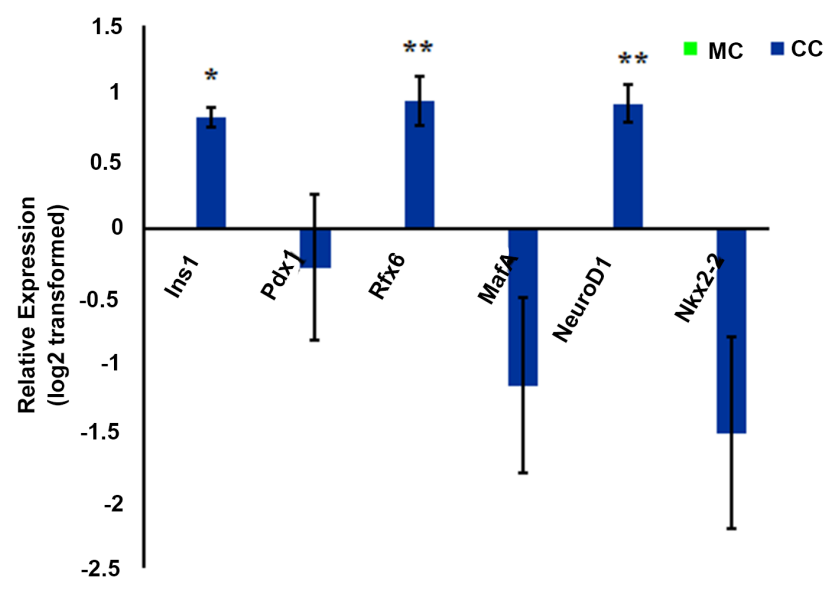

(a)

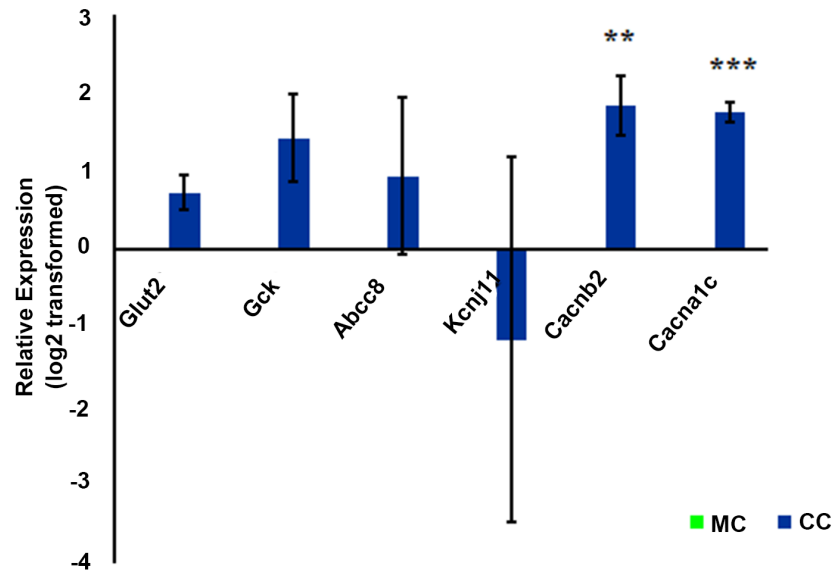

(b)

Figure 4. Relative expression of $\beta$-cell specific and GSIS related genes in PSC cocultured glucose responsive higher passage Min6 cells: (a) PSC cocultured glucose responsive higher passage Min6 cells showing increased expression of Ins1, Rfx6 and NeuroD1 with no significant changes in the expression of $P d x 1, M a f A$ and $N k x 2-2$, similar to PSC cocultured glucose unresponsive higher passage Min6 cells ( $\mathrm{n}=3$ ); (b) Significant upregulation of Cacnb2 and Cacna1c calcium channels with no alteration of other studied GSIS genes in cocultured glucose responsive higher passage Min6 cells, confirms that PSC secreted factors influence the expression of $\beta$-cell specific and GSIS associated genes in higher passage Min6 cells $(n=3)$. $\beta$ actin was used as an internal control to normalize the target gene expression and obtained fold changes were log transformed. Each target gene studied was analyzed in duplicates. Data are represented as mean \pm SEM. ${ }^{\star} p \leq 0.008,{ }^{* *} p \leq 0.05,{ }^{* *} p \leq 0.005$ Vs monocultured cells. 
were decreased without apparent changes in $p d x-1$ expression in Min6 cells exposed to PSC secretions in qRT-PCR validation study. Such changes related to Ins 1 gene expression were unaccompanied by changes in genes related to insulin secretory pathway. The enhanced expression of $R f_{x} 6$ and NeuroD1 suggests that $R f x 6$, either on its own or in combination with NeuroD1 [36], does influence expression of Ins1 gene. These results gain credence from observations made in an earlier study suggesting the importance of $R f_{x} 6$ [37] [38], on $\beta$-cell insulin gene expression.

Despite the increased expression of $R f x 6$, which influences GSIS related changes [37] [38], our studies did not reveal altered expression of GSIS associated genes in response to PSC secretions on Min6 cells. Results obtained with indirect coculture did not reveal changes in GSIS of Min6 cells exposed to PSCs. Recent in vitro coculture studies presented varied results on influence of PSCs on GSIS response [13]-[18]. Studies involving indirect cocultue of PSCs and its secretions with RINm-5F and INS-1 cell lines reported decreased insulin secretion [14] [32], while direct coculture of mouse islets in presence of PSCs caused increased insulin secretion [33]. While considering the response of insulin secreting cells to PSCs under in vitro conditions, the innate ability of cells to respond to glucose challenges is of considerable importance. It is generally held that RINm-5F cells are not responsive to glucose challenges [39] [40], and the ability of Min6 cells to respond to glucose depends on the number of passages they undergo [41] [42].

In our study we employed Min6 cells of higher passage (P53-64) and examined their insulin secretory responses. These cells did not exhibit much change in their GSIS response either in monoculture or coculture. Such an observation may be ascribed to the reported inability of glucose unresponsive higher passage Min6 cells to high glucose challenge [41] [42]. This result also indicates the inability of PSC secretions to restore the lost ability of insulin secretion of higher passage Min6 cells to glucose challenge. In order to verify such an inference, we examined GSIS of lower passage Min6 cells (P11) that were cultured to higher passage (P53-64). Results of this experiment as shown in Figure 3 (a) demonstrated the ability of such cells not only to respond to glucose challenge but also confirmed that PSC secretions further enhance insulin release by Min6 cells. The ability of higher passage Min6 cells to respond to glucose challenge in presence of PSC secretions also denotes that the glucose responsive nature of Min6 cells is of key relevance for the PSCs to influence insulin secretory abilities of Min6 cells. It is apparent that results obtained upon in vitro studies might not reflect in vivo situation, more so under disease conditions. Extrapolating the results reported herein to a physiological context, we may infer that even though PSCs can innately influence insulin secretory abilities of $\beta$-cells, it is possible that such an ability might be diminished in pancreatic disease.

The nature of secretions made by PSCs has not been characterized in the present study. It is known that PSC secretions, including inflammatory cytokines and different growth factors, can not only influence the pancreatic milieu but 
also influence $\beta$-cell functions. Importantly, the nature of PSC secretions under in vivo disease conditions would largely determine their influence on $\beta$-cell functions. Despite these limitations, this is the first report on the influence of PSCs on transcriptome profiles as well as genes that are involved in the insulin synthesis and secretory pathway of higher passage Min6 cells. Further experiments including characterization of PSC secretome should yield important information about their influence on gene expression profiles and insulin secretory response from islet isolates obtained from diabetic conditions.

\section{Acknowledgements}

Mr. Ratnakar Reddy Bynigeri is thankful to Department of Science and Technology for providing the INSPIRE Fellowship (IF120436). We sincerely thank Prof. Subramanyam Chivukula for critically reviewing and editing the manuscript. We thank Mrs. Aparna and Ms. Steffie for their support with NGS and qRT-PCR experiments.

\section{References}

[1] Moore, W.T., Bowser, S.M., Fausnacht, D.W., Staley, L.L., Suh, K.S. and Liu, D. (2015) Beta Cell Function and the Nutritional State: Dietary Factors That Influence Insulin Secretion. Current Diabetes Reports, 15, 76. https://doi.org/10.1007/s11892-015-0650-1

[2] Backe, M.B., Moen, I.W., Ellervik, C., Hansen, J.B. and Mandrup-Poulsen, T. (2016) Iron Regulation of Pancreatic Beta-Cell Functions and Oxidative Stress. Annual Review of Nutrition, 17, 241-273. https://doi.org/10.1146/annurev-nutr-071715-050939

[3] Carlessi, R., Keane, K.N., Mamotte, C. and Newsholme, P. (2017) Nutrient Regulation of $\beta$-Cell Function: What Do Islet Cell/Animal Studies Tell Us? European Journal of Clinical Nutrition, 71, 890-895. https://doi.org/10.1038/ejen.2017.49

[4] Lu, H., Koshkin, V., Allister, E.M., Gyulkhandanyan, A.V. and Wheeler, M.B. (2010) Molecular and Metabolic Evidence for Mitochondrial Defects Associated with Beta-Cell Dysfunction in a Mouse Model of Type 2 Diabetes. Diabetes, 59, 448-459. https://doi.org/10.2337/db09-0129

[5] Russo, G.T., Giorda, C.B., Cercone, S., Nicolucci, A., Cucinotta, D. and Beta Decline Study Group (2014) Factors Associated with Beta-Cell Dysfunction in Type 2 Diabetes: The BETADECLINE Study. PLoS One, 9, e109702. https://doi.org/10.1371/journal.pone.0109702

[6] Fu, Z., Gilbert, E.R. and Liu, D. (2013) Regulation of Insulin Synthesis and Secretion and Pancreatic Beta-Cell Dysfunction in Diabetes. Current Diabetes Reviews, 1, 25-53. https://doi.org/10.2174/157339913804143225

[7] Skrha, J. (2006) Pancreatic Hormones and Hormonal Regulation of Insulin Secretion. Casopis Lekaru Ceskych, 145, 599-605.

[8] Holst, J.J. and Gromada, J. (2004) Role of Incretin Hormones in the Regulation of Insulin Secretion in Diabetic and Nondiabetic Humans. American Journal of Physiology-Endocrinology and Metabolism, 287, E199-E206. https://doi.org/10.1152/ajpendo.00545.2003

[9] Keane, K.N., Cruzat, V.F., Carlessi, R., de Bittencourt Jr., P.I. and Newsholme, P. (2015) Molecular Events Linking Oxidative Stress and Inflammation to Insulin Re- 
sistance and $\beta$-Cell Dysfunction. Oxidative Medicine and Cellular Longevity, 2015, Article ID: 181643. https://doi.org/10.1155/2015/181643

[10] Aamodt, K.I. and Powers, A.C. (2017) Signals in the Pancreatic Islet Microenvironment Influence $\beta$-Cell Proliferation. Diabetes, Obesity and Metabolism, 19, 124-136. https://doi.org/10.1111/dom.13031

[11] Xia, C., Rao, X. and Zhong, J. (2017) Role of T Lymphocytes in Type 2 Diabetes and Diabetes-Associated Inflammation. Journal of Diabetes Research, 2017, Article ID: 6494795. https://doi.org/10.1155/2017/6494795

[12] Hasnain, S.Z., Prins, J.B. and McGuckin, M.A. (2016) Oxidative and Endoplasmic Reticulum Stress in $\beta$-Cell Dysfunction in Diabetes. Journal of Molecular Endocrinology, 56, R33-R54. https://doi.org/10.1530/JME-15-0232

[13] Homo-Delarche, F., Calderari, S., Irminger, J.C., Gangnerau, M.N., Coulaud, J., Rickenbach, K., Dolz, M., Halban, P., Portha, B. and Serradas, P. (2006) Islet Inflammation and Fibrosis in a Spontaneous Model of Type 2 Diabetes, the GK Rat. Diabetes, 55, 1625-1633. https://doi.org/10.2337/db05-1526

[14] Kikuta, K., Masamune, A., Hamada, S., Takikawa, T., Nakano, E. and Shimosegawa, T. (2013) Pancreatic Stellate Cells Reduce Insulin Expression and Induce Apoptosis in Pancreatic $\beta$-Cells. Biochemical and Biophysical Research Communications, 433, 292-297. https://doi.org/10.1016/j.bbrc.2013.02.095

[15] Saito, R., Yamada, S., Yamamoto, Y., Kodera, T., Hara, A., Tanaka, Y., Kimura, F., Takei, I., Umezawa, K. and Kojima, I. (2012) Conophylline Suppresses Pancreatic Stellate Cells and Improves Islet Fibrosis in Goto-Kakizaki Rats. Endocrinology, 153, 621-630. https://doi.org/10.1210/en.2011-1767

[16] Pavan Kumar, P., Radhika, G., Rao, G.V., Pradeep, R., Subramanyam, C., Talukdar, R., Reddy, D.N. and Sasikala, M. (2012) Interferon $\gamma$ and Glycemic Status in Diabetes Associated with Chronic Pancreatitis. Pancreatology, 12, 65-70. https://doi.org/10.1016/j.pan.2011.12.005

[17] Shaw, V.E., Lane, B., Jenkinson, C., Cox, T., Greenhalf, W., Halloran, C.M., Tang, J., Sutton, R., Neoptolemos, J.P. and Costello, E. (2014) Serum Cytokine Biomarker Panels for Discriminating Pancreatic Cancer from Benign Pancreatic Disease. Molecular Cancer, 13, 114. https://doi.org/10.1186/1476-4598-13-114

[18] Yako, Y.Y., Kruger, D., Smith, M. and Brand, M. (2016) Cytokines as Biomarkers of Pancreatic Ductal Adenocarcinoma: A Systematic Review. PLoS ONE, 11, e0154016.

[19] Ghassem-Zadeh, S., Gaida, M.M., Szanyi, S., Acha-Orbea, H., Frossard, J.L., Hinz, U., Hackert, T., Strobel, O. and Felix, K. (2017) Distinct Pathophysiological Cytokine Profiles for Discrimination between Autoimmune Pancreatitis, Chronic Pancreatitis, and Pancreatic Ductal Adenocarcinoma. Journal of Translational Medicine, 15, 126. https://doi.org/10.1186/s12967-017-1227-3

[20] Aoki, H., Ohnishi, H., Hama, K., Shinozaki, S., Kita, H., Yamamoto, H., Osawa, H., Sato, K., Tamada, K. and Sugano, K. (2006) Existence of Autocrine Loop between Interleukin-6 and Transforming Growth Factor- $\beta_{1}$ in Activated Rat Pancreatic Stellate Cells. Journal of Cellular Biochemistry, 99, 221-228.

https://doi.org/10.1002/jcb.20906

[21] Nagathihalli, N.S., Castellanos, J.A., VanSaun, M.N., Dai, X., Ambrose, M., Guo, Q., Xiong, Y. and Merchant, N.B. (2016) Pancreatic Stellate Cell Secreted IL-6 Stimulates STAT3 Dependent Invasiveness of Pancreatic Intraepithelial Neoplasia and Cancer Cells. Oncotarget, 7, 65982-65992.

[22] Ohnishi, N., Miyata, T., Ohnishi, H., Yasuda, H., Tamada, K., Ueda, N., Mashima, H. and Sugano, K. (2003) Activin A Is an Autocrine Activator of Rat Pancreatic 
Stellate Cells: Potential Therapeutic Role of Follistatin for Pancreatic Fibrosis. Gut, 52, 1487-1493. https://doi.org/10.1136/gut.52.10.1487

[23] Pothula, S.P., Xu, Z., Goldstein, D., Biankin, A.V., Pirola, R.C., Wilson, J.S. and Apte, M.V. (2016) Hepatocyte Growth Factor Inhibition: A Novel Therapeutic Approach in Pancreatic Cancer. British Journal of Cancer, 114, 269-280. https://doi.org/10.1038/bjc.2015.478

[24] Suzuki, T., Imai, J., Yamada, T., Ishigaki, Y., Kaneko, K., Uno, K., Hasegawa, Y., Ishihara, H., Oka, Y. and Katagiri, H. (2011) Interleukin-6 Enhances Glucose-Stimulated Insulin Secretion from Pancreatic $\beta$-Cells: Potential Involvement of the PLC-IP ${ }_{3}$-Dependent Pathway. Diabetes, 60, 537-547. https://doi.org/10.2337/db10-0796

[25] Shibata, H., Yasuda, H., Sekine, N., Mine, T., Totsuka, Y. and Kojima, I. (1993) Activin A Increases Intracellular Free Calcium Concentrations in Rat Pancreatic Islets. FEBS Letters, 329, 194-198. https://doi.org/10.1016/0014-5793(93)80220-O

[26] Furukawa, M., Nobusawa, R., Shibata, H., Eto, Y. and Kojima, I. (1995) Initiation of Insulin Secretion in Glucose-Free Medium by Activin A. Molecular and Cellular Endocrinology, 113, 83-87. https://doi.org/10.1016/0303-7207(95)03617-G

[27] Florio, P., Luisi, S., Marchetti, P., Lupi, R., Cobellis, L., Falaschi, C., Sugino, H., Navalesi, R., Genazzani, A.R. and Petraglia, F. (2000) Activin A Stimulates Insulin Secretion in Cultured Human Pancreatic Islets. Journal of Endocrinological Investigation, 23, 231-234. https://doi.org/10.1007/BF03343713

[28] Brown, M.L., Ungerleider, N., Bonomi, L., Andrzejewski, D., Burnside, A. and Schneyer, A. (2014) Effects of Activin A on Survival, Function and Gene Expression of Pancreatic Islets from Non-Diabetic and Diabetic Human Donors. Islets, 6, e1017226. https://doi.org/10.1080/19382014.2015.1017226

[29] Yeung, T.Y., Seeberger, K.L., Kin, T., Adesida, A., Jomha, N., Shapiro, A.M. and Korbutt, G.S. (2012) Human Mesenchymal Stem Cells Protect Human Islets from Pro-Inflammatory Cytokines. PLoS ONE, 7, e38189. https://doi.org/10.1371/journal.pone.0038189

[30] Lee, E., Ryu, G.R., Ko, S.H., Ahn, Y.B. and Song, K.H. (2017) A Role of Pancreatic Stellate Cells in Islet Fibrosis and $\beta$-Cell Dysfunction in Type 2 Diabetes Mellitus. Biochemical and Biophysical Research Communications, 485, 328-334. https://doi.org/10.1016/j.bbrc.2017.02.082

[31] Reddy, R., Talukdar, R., Sasikala, M., Pavan Kumar, P., Maheshwari, A. and Rao, G.V. (2013) Pancreatic Stellate Cells Contribute to Intra Islet Inflammatory Milieu in Chronic Pancreatitis. Indian Journal of Gastroenterology, 32, A113.

[32] Zha, M., Xu, W., Zhai, Q., Li, F., Chen, B. and Sun, Z. (2014) High Glucose Aggravates the Detrimental Effects of Pancreatic Stellate Cells on $\beta$-Cell Function. International Journal of Endocrinology, 2014, Article ID: 165612.

https://doi.org/10.1155/2014/165612

[33] Zang, G., Sandberg, M., Carlsson, P.O., Welsh, N., Jansson, L. and Barbu, A. (2015) Activated Pancreatic Stellate Cells Can Impair Pancreatic Islet Function in Mice. Upsala Journal of Medical Sciences, 120, 169-180. https://doi.org/10.3109/03009734.2015.1032453

[34] Apte, M.V., Haber, P.S., Applegate, T.L., Norton, I.D., Mc Caughan, G.W., Korsten, M.A., Pirola, R.C. and Wilson, J.S. (1998) Periacinar Stellate Shaped Cells in Rat Pancreas: Identification, Isolation, and Culture. Gut, 43, 128-133. https://doi.org/10.1136/gut.43.1.128

[35] Bayan, J.A., Peng, Z., Zeng, N., He, L., Chen, J. and Stiles, B.L. (2015) Crosstalk be- 
tween Activated Myofibroblasts and $\beta$-Cells in Injured Mouse Pancreas. Pancreas, 44, 1111-1120. https://doi.org/10.1097/MPA.0000000000000431

[36] Andrali, S.S., Sampley, M.L., Vanderford, N.L. and Ozcan, S. (2008) Glucose Regulation of Insulin Gene Expression in Pancreatic $\beta$-Cells. Biochemical Journal, 415, 1-10. https://doi.org/10.1042/BJ20081029

[37] Piccand, J., Strasser, P., Hodson, D.J., Meunier, A., Ye, T., Keime, C., Birling, M.C., Rutter, G.A. and Gradwohl, G. (2014) $R f_{x} 6$ Maintains the Functional Identity of Adult Pancreatic $\beta$ Cells. Cell Reports, 9, 2219-2232. https://doi.org/10.1016/j.celrep.2014.11.033

[38] Chandra, V., Albagli-Curiel, O., Hastoy, B., Piccand, J., Randriamampita, C., Vaillant, E., Cavé, H., Busiah, K., Froguel, P., Vaxillaire, M., Rorsman, P., Polak, M. and Scharfmann, R. (2014) RFX6 Regulates Insulin Secretion by Modulating $\mathrm{Ca}^{2+} \mathrm{Ho}$ meostasis in Human $\beta$ Cells. Cell Reports, 9, 2206-2218.

https://doi.org/10.1016/j.celrep.2014.11.010

[39] Gazdar, A.F., Chick, W.L., Oie, H.K., Sims, H.L., King, D.L., Weir, G.C. and Lauris, V. (1980) Continuous, Clonal, Insulin-and Somatostatin-Secreting Cell Lines Established from a Transplantable Rat Islet Cell Tumor. Proceedings of the National Academy of Sciences of the United States of America, 77, 3519-3523. https://doi.org/10.1073/pnas.77.6.3519

[40] Praz, G.A., Halban, P.A., Wollheim, C.B., Blondel, B., Strauss, A.J. and Renold, A.E. (1983) Regulation of Immunoreactive-Insulin Release from a Rat Cell Line (RINm5F). Biochemical Journal, 210, 345-352. https://doi.org/10.1042/bj2100345

[41] Cheng, K., Delghingaro-Augusto, V., Nolan, C.J., Turner, N., Hallahan, N., Andrikopoulos, S. and Gunton, J.E. (2012) High Passage MIN6 Cells Have Impaired Insulin secretion with Impaired Glucose and Lipid Oxidation. PLOS ONE, 7, e40868. https://doi.org/10.1371/journal.pone.0040868

[42] O’Driscoll, L., Gammell, P., McKiernan, E., Ryan, E., Jeppesen, P.B., Rani, S. and Clynes, M. (2006) Phenotypic and Global Gene Expression Profile Changes between Low Passage and High Passage MIN-6 Cells. Journal of Endocrinology, 238, 665-676. https://doi.org/10.1677/joe.1.06894 